\title{
Transoral endoscopic thyroidectomy vestibular approach in a patient with Class III goitre (operative steps and video)
}

\author{
Zeyang Liu ${ }^{1} \wedge$, Zan $\mathrm{Li}^{1}$, Xiaowei Peng ${ }^{1}$, Bo Zhou ${ }^{1}$, Chunliu $\mathrm{Lv}^{1}$, Liang $\mathrm{Yi}^{1}$, Hui $\mathrm{Li}^{1}$, Wen Peng ${ }^{1}$, \\ Zhiyuan Wang ${ }^{2}$, Jigang $\mathbf{L i}^{3}$ \\ ${ }^{1}$ Department of Oncology Plastic Surgery/Head and Neck Surgery, ${ }^{2}$ Department of Ultrasound, ${ }^{3}$ Department of Pathology, Hunan Cancer Hospital/ \\ the Affiliated Cancer Hospital of Xiangya Medical School, Central South University, Changsha, China \\ Correspondence to: Xiaowei Peng. Department of Oncology Plastic Surgery/Head and Neck Surgery, Hunan Cancer Hospital/the Affiliated Tumor \\ Hospital of Xiangya Medical School, Central South University, Changsha 410008, Hunan, China. Email: xiaoweipeng619@163.com.
}

\begin{abstract}
Transoral endoscopic thyroidectomy vestibular approach (TOETVA) has recently become a hot research topic due to the advantage of leaving no scar, but, according to most centers, its indication is restricted to the size of thyroid gland. Here we report a case of a female patient with Class III goitre who successfully underwent TOETVA (video attached). A 53-year-old woman with a previous history of chest keloidosis presented with a history of neck swelling for 3 years and was diagnosed as Hashimoto's thyroiditis with no nodules. The patient insisted that she undergo a TOETVA procedure in our hospital. Compared to the traditional TOETVA, several techniques were applied in this operation to ensure the resection and removal of the thyroid gland: with the dissection of the mental nerve and using the lateral approach to the thyroid gland. The total volume of thyroid gland was $205 \mathrm{~mL}$. The operating time was $195 \mathrm{~min}$. No complications were incurred. The numbness of the lip and chin was measured by the "two-points discrimination" method with several aspects (touch, pain, temperature) at different times to evaluate mental nerve injury. She felt the numbness during the first operative day but it was almost completely relieved in the third postoperative month. To our knowledge, this is the largest thyroid gland reported removed with TOETVA procedure. By carefully designing the operative steps, it is feasible to use the transoral approach in patients who have a benign thyroid disease with a Class III goitre if the patient strongly desires that operation.
\end{abstract}

Keywords: Transoral endoscopic thyroidectomy; transoral endoscopic thyroidectomy vestibular approach (TOETVA); goiter; indication; case report

Submitted Jan 19, 2020. Accepted for publication Sep 03, 2020.

doi: 10.21037/gs-20-147

View this article at: http://dx.doi.org/10.21037/gs-20-147

\section{Introduction}

Cunchuan Wang reported a transoral endoscopic thyroidectomy vestibular approach (TOETVA) in 2012 (1), and the modification of that approach, currently known as TOETVA was first reported by Angkoon Anuwong in 2016 (2). This approach has gradually become accepted worldwide and has quickly become a widely discussed topic due to the advantage of leaving no scars.
The use of TOETVA is limited to some extent. According to the criteria from different centers, most agree that the thyroid gland should be small enough, $<25-$ $40 \mathrm{~mL}$, depending on the center (3-6), otherwise it is difficult to resect the tissue under endoscopy and more difficult to remove in a transoral way.

However, with meticulous dissection of the mental nerve and a lateral approach to the thyroid gland, on 20 September 2019, we successfully completed TOETVA for

^ ORCID: 0000-0001-9397-1006. 

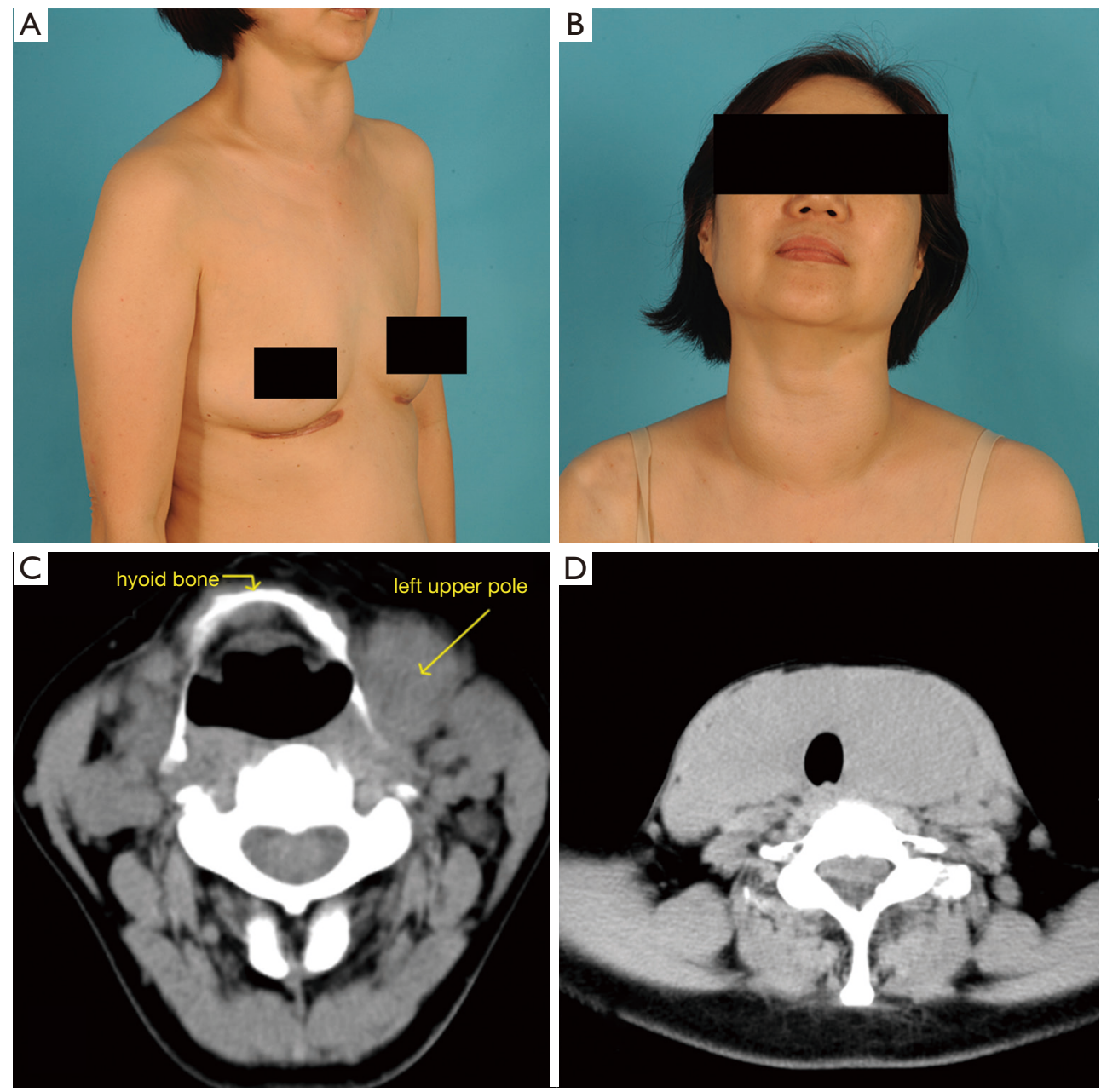

Figure 1 Appearance and CT scan before surgery. (A,B) Chest keloid and neck swelling were clearly seen; (C,D) CT scan showed the left upper pole was higher than the hyoid bone.

a female patient with a history of keloid scarring and a large goitre measuring $205 \mathrm{~mL}$ (Class III goitre). We present a video of this case report (Video 1).

We present the following article in accordance with CARE reporting checklist (available at http://dx.doi. org/10.21037/gs-20-147).

\section{Case presentation}

A 53-year-old female with a previous history of a chest keloid presented with neck swelling (Figure 1A,B). Three years prior she had been treated for a diagnosis of Hashimoto's thyroiditis (HT) and regularly used $25 \mu \mathrm{g}$ levothyroxine per day. One year ago, the neck swelling worsened and she was treated with an increase dose of
$100 \mu \mathrm{g}$ L-thyroxine per day. During that time, local surgeons suggested she have a thyroidectomy but she refused because of the fear of having a scar and a keloid. In September 2019 she went to our hospital for further treatment. She did not complain about dysphagia or dyspnea. The Swallowing Impairment Score [SIS-6, to evaluate the degree of swallowing disorder (7)] was 4 points. The ultrasound image showed that the left thyroid lobe was $70 \mathrm{~mm} \times 46 \mathrm{~mm} \times 35 \mathrm{~mm}$; the right lobe was $66 \mathrm{~mm} \times$ $43 \mathrm{~mm} \times 33 \mathrm{~mm}$ and the isthmus of the thyroid was $20-\mathrm{mm}$ thick. No nodules were found in either lobe. A CT scan found that the upper pole of left gland was higher than the level of the hyoid bone (Figure $1 C, D$ ). The patient was very eager for TOETVA and was informed of the risk that the procedure might change to open thyroidectomy (OT) if the 
tissue was too large to remove.

There were no abnormal findings from a flexible nasopharyngeal laryngoscopy. Thyroid hormones were thyroglobulin (TG): $0.036 \mathrm{ng} / \mathrm{mL}$, total thyroxine (TT4) $8.848 \mu \mathrm{g} / \mathrm{mL}$, total triiodothyronine (TT3) $0.920 \mathrm{ng} / \mathrm{mL}$, thyroid-stimulating hormone (TSH) $0.267 \mu \mathrm{IU} / \mathrm{mL}$, thyroid peroxidase antibody (TPO-Ab) 68.221 IU/mL, and thyroglobulin antibody (TG-Ab) $78.112 \mathrm{IU} / \mathrm{mL}$. Other preoperative examinations showed that she could tolerate general anesthesia. The principal surgeon who performed this operation had extensive experience (over 400 cases).

All procedures performed in studies involving human participants were in accordance with the ethical standards of the institutional and/or national research committee(s) and with the Helsinki Declaration (as revised in 2013). Written informed consent was obtained from the patient.

\section{Methods}

\section{Preoperative preparation}

No oral infection was found. The patient had a general endotracheal anesthesia through oral intubation in a supine position with a pillow placed under her shoulder. Because the incision was in the oral cavity (which might cause infection), an intravenous infusion of cefamandole was prepared to use during the surgery.

\section{Mental nerve dissection}

After disinfection three times, the main surgeon sat near the patient's head and one assistant sat on the left side of the patient. The lower lip was retracted by the assistant to expose the oral vestibule.

The process of mental nerve dissection has been described in detail by Peng et al. (8): the design of the incision began at the midpoint of the vestibule about $1 \mathrm{~cm}$ inferior to the gingival edge. A curved mosquito forceps was used for separating the submucosa, and the incision was lengthened horizontally from both ends of the mucosa incision. The branches of the mental nerves were exposed. Muscle was incised at the middle of the vestibule under the mucosa incision and separated downward to the mandible surface.

\section{Building working space}

Expansion solution with a volume of $5 \mathrm{~mL}(1 \mathrm{mg}$ adrenaline in $500 \mathrm{~mL}$ saline) was injected subcutaneously from the chin to the hyoid bone. A blunt tip dilator was then used for creating a subcutaneous tunnel towards suprasternal fossa. After two 5-mm trocars were separately inserted into the inner side of the inner branches of the mental nerve and a $10-\mathrm{mm}$ trocar was inserted into the middle tunnel, $\mathrm{CO}_{2}$ with a constant pressure of $6 \mathrm{mmHg}$ was injected into the space. An electrocoagulation hook diathermy and an ultrasonic scalpel were alternately used to reduce bleeding. The space was established down to the sternal notch with the lateral border at the sternocleidomastoid muscles. The middle of the anterior neck skin was lifted with a Vicryl Plus suture 4-0 (Ethicon, Inc.) and fixed to an arc-shaped omnidirectional fixed device above the patient's neck. This arc-shaped omnidirectional fixed device was first used in our study in 2017 (9) (patent: No. 201821210473.4 registered under China).

\section{Resection of right thyroid gland and istbmus}

The linea alba was incised. After separation from the right gland, the strap muscles were then retracted to the right with a 4-0 suture fixed to the arc-shaped device. The pyramidal lobe was separated from the trachea by an electrocoagulation hook diathermy. An atraumatic grasping forceps was used for grasping the right thyroid gland. Part of the sternothyroideus was resected for a better view. After the superior thyroid artery and veins were severed, the upper pole can be separated completely. The recurrent laryngeal nerve (RLN) was carefully identified with the help of intraoperative neuromonitoring (IONM). Berry's ligament was cut. After resection the gland was not immediately removed from the workspace. If it had been removed, the oral incision would need to have been enlarged, which would then cause $\mathrm{CO}_{2}$ leakage.

\section{Resection of the left thyroid gland}

As the upper pole of left gland was at the level of the hyoid bone shown in the CT, it was difficult to expose it in a traditional way as it was for the incision of the right lobe. Therefore, we decided to use "the lateral approach to the thyroid gland" (10): The boundary between the lateral strap muscles and the medial sternocleidomastoid muscle was opened using the electrocoagulation hook. The omohyoid muscle was in the way, so it was transected. The potential space between the left gland and the left strap muscles was then opened from the lateral side to the medial side and the 
upper pole of the thyroid was then revealed. The following steps were similar to those used for the right lobe. There was some residual tissue. The parathyroid and the RLN were carefully identified and protected under IONM.

\section{Removal and measurement}

The left gland was put into a specimen bag and then removed through the subcutaneous tunnel which was originally used for the $10-\mathrm{mm}$ trocar insertion. Because the size of tissue was large, we extended the tunnel along

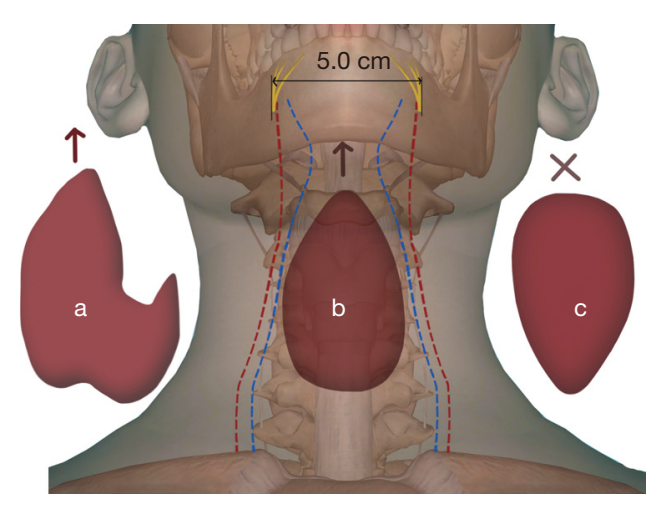

Figure 2 How to pull out the Class III goitre. a: correct position of right lobe and isthmus; b: correct position of left lobe; c: wrong position of left lobe. Red dash lines represent the boundary of tunnel in this case. Blue dash lines represent the boundary of tunnel in a normal case.

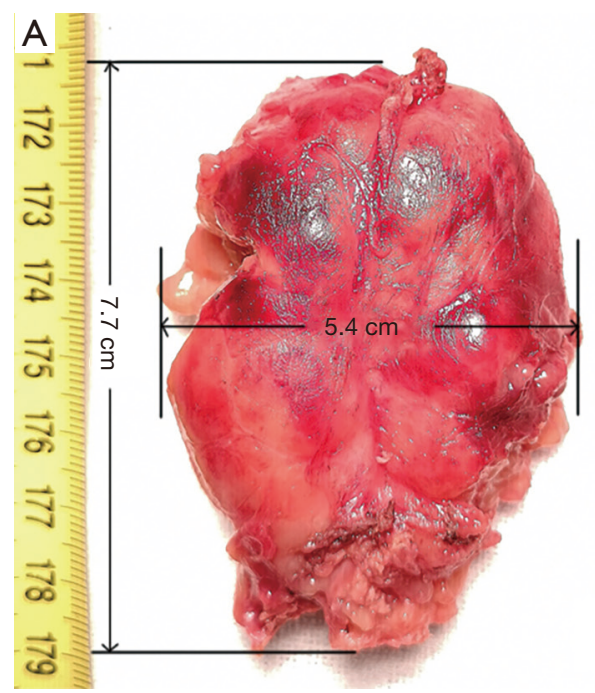

Figure 3 Thyroid gland. (A) Left lobe; (B) right lobe and isthmus. the surface of the mandible. The tunnel was enlarged near the two sides of the mental foramen with an electrotome. Therefore, it became easier to remove the entire tissue. In addition, there was a certain position for its taking out, which was "let the thinner part go first and vertically", otherwise it might be difficult to deliver the specimen (Figure 2). The right lobe and isthmus were removed successfully in the same way by using a new specimen bag.

There was still some residual tissue which needed to be removed. However, the tunnel needed to be enlarged for removal, which would surely have cause air leakage. Thus, the $10-\mathrm{mm}$ trocar was wrapped with a latex glove, so that the tunnel could be sealed to solve this problem. As the main part of the gland was taken out, the working space was spacious and the residual tissue was easily removed and was taken out in a new specimen bag.

The left gland measured $7.7 \mathrm{~cm} \times 5.4 \mathrm{~cm} \times 4.0 \mathrm{~cm}$ (without its residual tissue) (Figure $3 A$ ), a volume of $90 \mathrm{~mL}$ (with the residual tissue). A measuring vessel containing normal saline was used for measuring its volume (minimum scale: $5 \mathrm{~mL}$, approximate read: $1 \mathrm{~mL}$ ). The right gland and isthmus measured $10.1 \mathrm{~cm} \times 9.0 \mathrm{~cm} \times 4.0 \mathrm{~cm}$ (Figure $3 B$ ), a volume of $115 \mathrm{~mL}$. Both were sent for fast pathological examination, and there were no malignant findings.

\section{Closure}

The operational space was flushed with sterile water and then bleeding was meticulously checked and stopped.

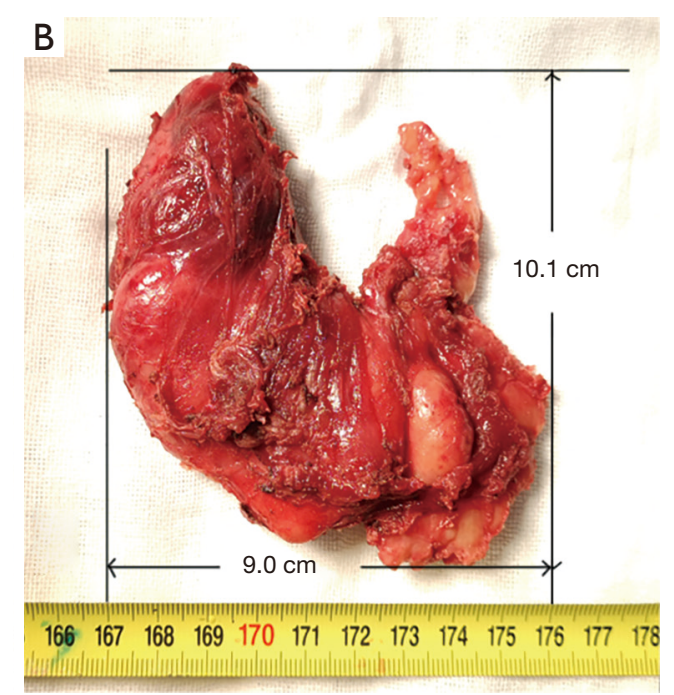



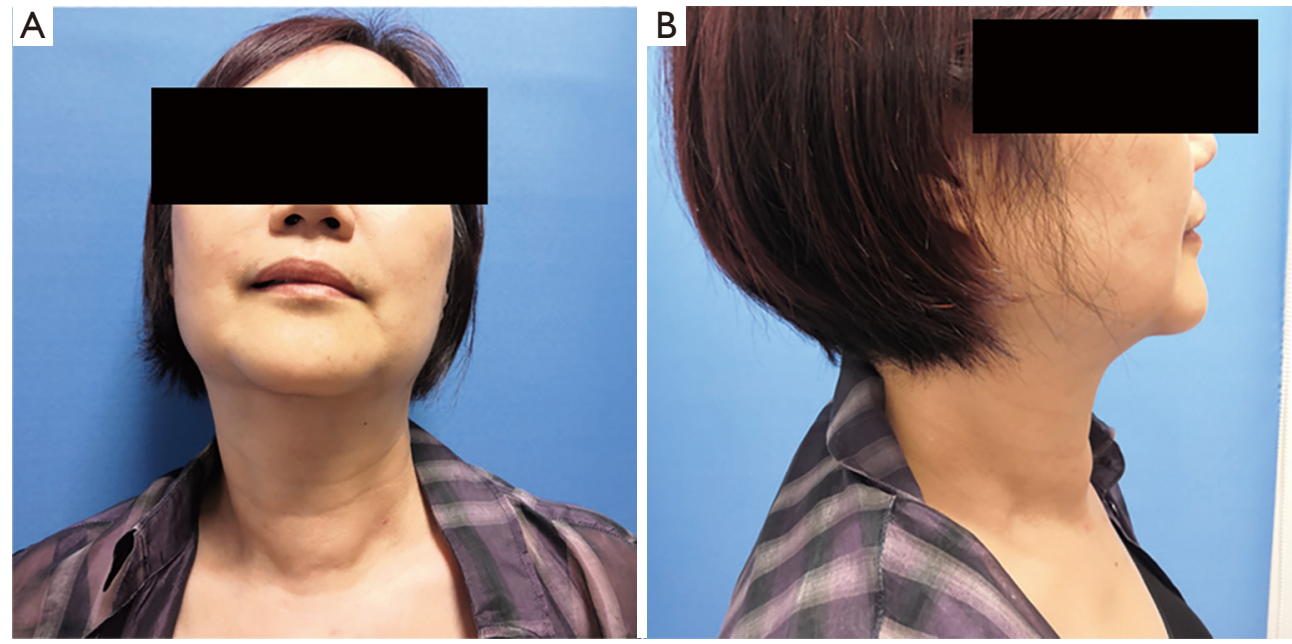

Figure 4 Appearance in postoperative month 3, no scar, no neck swelling. (A) Front view; (B) side view.

According to our previous study of the drainage in TOETVA, the volume of the patient's drainage was estimated to be greater than $150 \mathrm{~mL}$ in total (11). Thus, we considered it safe to install a drain. A central venous catheter was used as a drain tube. (Brand: Tuoren, outer diameter $1.7 \mathrm{~mm}$, inner diameter $1.0 \mathrm{~mm}$ ), which would result in a smaller scar than a normal drainage tube (11). After the oral incision was sutured with a running sutured using 5-0 absorbable suture material, the catheter was connected to a high negative drainage bottle (Brand: German Pfm Medical Mepro Gmbh, volume: $400 \mathrm{~mL}$, pressure: $98 \mathrm{kPa}$ ). There was about a $50 \mathrm{~mL}$ blood loss. The whole operation time was $195 \mathrm{~min}$.

\section{Postoperative management}

The patient was allowed to have a liquid diet 6 hours later. During the first day an ice compress was put behind the chin to relieve swelling. Her pain score was assessed by using the Visual Analogue Scale/Score (VAS) that ranges between 0 to 10 . The lower the score, the less pain she experienced. In the first postoperative day (POD1), the VAS was 3 points. It had dropped to 1 when she was discharged on the third postoperative day (POD3). Although she did not complain about hoarseness, her vocal cord function was still checked by laryngoscopy the next day, and showed a normal result. Intravenous antibiotics were given for 3 days to prevent infection and intravenous calcium for 2 days to prevent temporary low calcium. The drainage tube was removed 3 days after the operation and the total drainage volume was $180 \mathrm{~mL}$. A blood test of thyroid function in the third day showed normal parathyroid hormone $(\mathrm{PTH})$ (30.67 pmol/L) and $\mathrm{Ca}^{2+}(2.4 \mathrm{mmol} / \mathrm{L})$.

\section{Follow-up}

No complications developed. She was asked to take $100 \mu \mathrm{g}$ levothyroxine everyday and to exercise the neck everyday. She was very satisfied with the operation. Figure 4 shows her appearance in postoperative month 3 (POM3). A tiny scar left by the drain disappeared and her SIS-6 dropped to 1 point after one month of her discharge.

The sensation of skin (lower lip, chin, under the chin) was measured for several aspects (touch, pain, temperature) times different times (pre-operation, POD1, POD3, POM1, POM3) to assess mental nerve injury. This method was originated by Bartling et al. (12) and then refined for our study. A cotton swab lightly touched on the left side of the lower lip, and then touched the right side. She was asked whether she could tell the two-point discrimination. If yes, the distance between two points was gradually reduced until the patient could not discriminate two points of contact. The distance was recorded as the minimal identifiable distance in millimeter (Table 1). A similar technique was used to test for the ability to perceive pain; but a 27 -gauge needle was used instead of swabs. For the temperature test an iced metal stick and a warm metal stick (about 43 centigrade) were used. 
Table 1 The sensation of skin using the method of "two-point discrimination" to evaluate the mental nerve injury in a patient after TOETVA

\begin{tabular}{|c|c|c|c|c|c|c|c|c|c|c|c|c|}
\hline \multirow{2}{*}{$\begin{array}{l}\text { Minimal } \\
\text { identifiable } \\
\text { distance }(\mathrm{mm})\end{array}$} & \multicolumn{4}{|c|}{ Lower lip } & \multicolumn{4}{|c|}{ Chin } & \multicolumn{4}{|c|}{ Under the chin } \\
\hline & Touch & Pain & Ice & Warm & Touch & Pain & Ice & Warm & Touch & Pain & Ice & Warm \\
\hline Pre-op & 3 & 4 & 4 & 4 & 5 & 5 & 5 & 5 & 6 & 6 & 5 & 6 \\
\hline POD1 & 12 & 14 & 13 & 13 & 15 & 15 & 15 & 15 & 20 & 18 & 18 & 18 \\
\hline POM1 & 6 & 7 & 6 & 6 & 8 & 7 & 7 & 7 & 10 & 10 & 10 & 10 \\
\hline РОM3 & 5 & 5 & 4 & 4 & 5 & 6 & 5 & 5 & 7 & 7 & 6 & 6 \\
\hline
\end{tabular}

Pre-op, pre-operation; POD1, post-operative day 1; POD3, post-operative day3; POM1, post-operative month 1; POM3, post-operative month 3. TOETVA, transoral endoscopic thyroidectomy vestibular approach.

Table 2 Indication of TOETVA reported in various literature concerning the size of thyroid gland

\begin{tabular}{|c|c|c|c|c|c|c|}
\hline Study & \multicolumn{2}{|c|}{ Benign } & \multicolumn{2}{|r|}{ DTC } & Volume & $\begin{array}{l}\text { Thyroid } \\
\text { diameter }\end{array}$ \\
\hline $\begin{array}{l}\text { Chinese experts consensus } \\
\text { (2018 version) (3) }\end{array}$ & $\leq 4 \mathrm{~cm}$ & $\leq 4 \mathrm{~cm}$ & $\leq 2 \mathrm{~cm}$ & $\begin{array}{l}\leq 2 \mathrm{~cm} \text { and no } \\
\text { confluence }\end{array}$ & $\begin{array}{l}\text { Less than or equal to the Class } \\
\text { II goiter }\end{array}$ & - \\
\hline Zhang 2019, (4) & $<3.5 \mathrm{~cm}$ & - & - & - & $<25 \mathrm{~mL}$ & $\leq 10 \mathrm{~cm}$ \\
\hline Garstka 2019, (6) & $\leq 5 \mathrm{~cm}$ & - & $\leq 2 \mathrm{~cm}$ & - & $<40 \mathrm{~mL}$ & - \\
\hline Peng 2017, (9) & $\leq 5 \mathrm{~cm}$ & - & $<2 \mathrm{~cm}$ & - & - & - \\
\hline Peng 2020, (8) & $\leq 6 \mathrm{~cm}$ & - & $<2 \mathrm{~cm}$ & - & - & - \\
\hline
\end{tabular}

"-": data was not mentioned. Class II goiter: the goiter can be seen and touched on the neck, but not exceeding the outside of sternocleidomastoid muscle; Class III goiter: the goiter can be obviously seen and touched on the neck, and exceeding the outside of sternocleidomastoid muscle. DTC, differentiated thyroid cancer; TOETVA, transoral endoscopic thyroidectomy vestibular approach.

The blood test on POM3 showed; TG $<0.04 \mathrm{ng} / \mathrm{mL}$, TT4 $7.17 \mu \mathrm{g} / \mathrm{mL}$, TT3 $0.73 \mathrm{ng} / \mathrm{mL}$, TSH $18.32 \mu \mathrm{IU} / \mathrm{mL}$, TPO-Ab $8.894 \mathrm{IU} / \mathrm{mL}$, TG-Ab 6.256 IU/mL, and PTH $64.2 \mathrm{pg} / \mathrm{mL}$. The levels of TPO-Ab and TG-Ab were much lower than the preoperative levels.

\section{Discussion}

\section{Indications for TOETVA}

Unlike OT, the limited working space and endoscopic technique restricts the indication for TOETVA. The indications according to the size are listed in Table 2. Other indications: no evidence of clinical or radiographic lateral nodal metastasis or distant metastasis and no previous surgery or radiation of the neck $(3-6,8,9,13,14)$. No severe oral cavity infection, such as an abscess $(3,5,13)$. No invasion of the esophagus or trachea $(4,8,9)$. No history of chin augmentation by a silicone implant (13).

In this case, we challenged the current indications and succeeded. This success resulted from not only our technique but also from the patient's strong wishes and their trust, which was appreciated.

The actual size of the thyroid tissue was larger than what it was measured by ultrasound in this case, and this statement was also reported in Hongjuan's study (15). 
Possible reasons include the depth which the probe could detect was limited because her thyroid tissue was thick and behind the strap muscles. Thus, the boundaries of the posterior surface of the thyroid could not be clearly detected with ultrasound.

\section{Mental nerve dissection}

This technique was first mentioned by Xiaowei Peng and colleagues in 2017 (9). In 2019 he conducted a further study (10), a comparative trial between one group with mental nerve dissection and another group with the conventional three incisions, the most commonly known way of incision in TOETVA $(3,13,16)$. He pointed out its three advantages: to protect the mental nerve, to facilitate specimen removal, and to avoid the "chopsticks effect" (the interference between the endoscopic appliance in each hand and the endoscope).

It is our experience that an injury to the mental nerve can numb the mucosal and cutaneous surfaces of the lower lip and chin for 6-12 months. On the contrary, those whose mental nerve is not injured commonly feel a numb lower lip during the first month after the operation and this feeling is relieved during the first 3 months or sooner (8). In this case, the patient's mental nerve was dissected and protected during the operation. In the follow-up period we measured the numbness of different areas (lower lip, chin, under the chin) of innervation by the mental nerve as a measure of nerve injury. This method was feasible and straightforward. She complained about lip numbness during POD1, but it gradually resolved in POM1 and almost became normal in POM3.

During the specimen removal the distance between both sides of her mental nerve was $5.0 \mathrm{~cm}$, so the thyroid gland had to go through a narrow subcutaneous tunnel. We were cautious not to enlarge the tunnel to the two sides of the mental foramen unless the mental nerve had been carefully dissected. In this case, the tunnel was enlarged at the two sides of the mental foramen with an electrotome to make a better delivery for the large thyroid gland (Figure 3). Although dragging the nerve could not be avoided during the removal of the specimen bag due to the large size of tissue, we were sure that the integrity of the nerve was protected.

Additionally, there was little "chopsticks effect" in this case according to the main surgeon's perception. Because a larger incision can increase the mobility of the upper lip (the lip could be dragged to the level of the chin or even under the chin), compared to the conventional three incisions, the mobility of the two $5-\mathrm{mm}$ trocars increased and the chopsticks effect was minimized.

\section{Lateral approach to the thyroid gland}

This approach has been used in OT in cases where the upper pole of the thyroid was difficult to expose $(10,17)$, but it was not yet reported for use with TOETVA. To expose the upper lobe, it is more common to incise the cervical linea alba and to retract the strap muscles to the affected side, as we did while resecting the right thyroid gland in this case. However, for the left lobe the upper pole was large and at a high level to the hyoid bone. It was hidden beneath the strap muscles and could not have been thoroughly exposed no matter how hard the strap muscles were dragged if we had used a traditional approach like the right lobe. It was hard to visualize the left upper pole with the endoscope. Nor could it be seen by direct vision through the incision.

Therefore, the approach of the lateral strap muscles was applied. As is shown in the video, we grasped a part of the gland and the upper pole was dragged by its near tissue. It could not be seen thoroughly until it was fully dissected. If we loosened the grasp, the upper pole would retract back to its original position and be hidden. The first assistant also played an important role during this procedure, and had to know how to control the endoscope well to provide a better field of vision. The upper parathyroid gland was also preserved. In conclusion, this approach can be used not only in OT but also in TOETVA, which makes the dissection of the upper pole easier and safer.

\section{Other discussion}

IOMN has always been recommend in thyroid surgery for navigation and confirmation of the functional integrity of the RLN during both OT (18) and TOETVA (19). We highly recommend the use of IONM in cases like these.

$\mathrm{HT}$ is the most common endocrine disorder, as well as the most common cause of hypothyroidism. The fibrous variant of HT is characterized by an enlarged, hard, and lobulated thyroid (20). In this case, the patient had hypothyroidism for years and the size of the goitre gradually grew, which met the indication of thyroidectomy. Luckily, the thyroid gland was not stiff according to the surgeon's observations. Elastography can assess the risk of malignancy and provides information about the degree of hardness in tissue (21). However, we did not apply elastography before 
the surgery to quantify the stiffness of the goitre, which was a deficiency.

Thyroid hormone tests showed a satisfying result during the third postoperative month, as the level of TPO-Ab and TG-Ab dropped compared with the preoperative results. This proved that subtotal/total thyroidectomy is still one of the effective treatment for HT (20).

Additionally, we might have been too cautious about the postoperative treatment as we prolonged the use of antibiotics and intravenous calcium compared to other cases.

We do not recommend an unskilled surgeon perform this surgery on a patient with Class III goitre. We recommend that only those who have extensive surgical experience (at least 100 cases) proceed with this technique.

\section{Conclusions}

With the improved techniques above, it is possible to remove a benign goiter over $200 \mathrm{~mL}$ using TOETVA. By carefully designing the operative steps it is feasible to use the transoral approach in patients who have a benign thyroid disease with Class III goitre, if the patient strongly desires using this technique. Whether TOETVA can be applied in all the Class III goitre remains to be seen, far more clinical trials and evidence are needed.

\section{Acknowledgments}

Funding: This study is sponsored by Cancer Research Program of National Cancer Center (NCC2017A15), Hunan Hygiene and Health Committee (B2019096), the Science and Technology Project of Changsha City (kq1801103), the Natural Science Foundation of Hunan Province (2020JJ8019).

\section{Footnote}

Reporting Checklist: The authors have completed the CARE reporting checklist. Available at http://dx.doi.org/10.21037/ gs-20-147

Peer Review File: Available at http://dx.doi.org/10.21037/gs20-147

Conflicts of Interest: All authors have completed the ICMJE uniform disclosure form (available at http:// dx.doi.org/10.21037/gs-20-147). XP has a patent No.
201821210473.4 licensed to Hunan Cancer Hospital. The other authors have no conflicts of interest to declare.

Ethical Statement: The authors are accountable for all aspects of the work in ensuring that questions related to the accuracy or integrity of any part of the work are appropriately investigated and resolved. All procedures performed in studies involving human participants were in accordance with the ethical standards of the institutional and/or national research committee(s) and with the Helsinki Declaration (as revised in 2013). Written informed consent was obtained from the patient for publication of this manuscript and any accompanying images.

Open Access Statement: This is an Open Access article distributed in accordance with the Creative Commons Attribution-NonCommercial-NoDerivs 4.0 International License (CC BY-NC-ND 4.0), which permits the noncommercial replication and distribution of the article with the strict proviso that no changes or edits are made and the original work is properly cited (including links to both the formal publication through the relevant DOI and the license). See: https://creativecommons.org/licenses/by-nc-nd/4.0/.

\section{References}

1. Wang C, Zhai H, Liu W, et al. Thyroidectomy: a novel endoscopic oral vestibular approach. Surgery 2014;155:33-8.

2. Anuwong A. Transoral Endoscopic Thyroidectomy Vestibular Approach: A Series of the First 60 Human Cases. World J Surg 2016;40:491-7.

3. Wang P, Wu GY, Tian W, et al. Chinese Experts Consensus on Transoral Endoscopic Thyroidectomy Vestibular Approach (2018 edition). Chinese Journal of Practical Surgery 2018;38:1104-7.

4. Zhang D, Caruso E, Sun $\mathrm{H}$, et al. Classifying pain in transoral endoscopic thyroidectomy. J Endocrinol Invest 2019;42:1345-51.

5. Qu R, Wang J, Li J, et al. The Learning Curve for Surgeons Regarding Endoscopic Thyroidectomy via the Oral-vestibular Approach. Surg Laparosc Endosc Percutan Tech 2018;28:380-4.

6. Garstka ME, Alameer ES, Awwad SA, et al. Conventional Robotic Endoscopic Thyroidectomy for Thyroid Cancer. Endocrinol Metab Clin North Am 2019;48:153-63.

7. Lombardi CP, Raffaelli M, D'Alatri L, et al. Video-assisted thyroidectomy significantly reduces the risk of early 
postthyroidectomy voice and swallowing symptoms. World J Surg 2008;32:693-700.

8. Peng X, Li Z, Li H, et al. The clinical application of mental nerve dissection in transoral endoscopic thyroidectomy via an oral vestibular approach. Surg Endosc 2020;34:153-8.

9. Peng XW, Li H, Li Z, et al. Modified transoral endoscopic thyroid surgery for treatment of thyroid cancer: operative steps and video. Gland Surg 2017;6:742-4.

10. Singaporewalla RM, Tan BC, Rao AD. The lateral "backdoor" approach to open thyroid surgery: A comparative study. Asian J Surg 2018;41:384-8.

11. Liu Z, Peng X, Li Z, et al. Postoperative drain after transoral endoscopic thyroidectomy vestibular approach (TOETVA) with single incision. Surg Endosc 2020. [Epub ahead of print].

12. Bartling R, Freeman K, Kraut RA. The incidence of altered sensation of the mental nerve after mandibular implant placement. J Oral Maxillofac Surg 1999;57:1408-12.

13. Jongekkasit I, Jitpratoom P, Sasanakietkul T, et al. Transoral Endoscopic Thyroidectomy for Thyroid Cancer. Endocrinol Metab Clin North Am 2019;48:165-80.

14. Wang Y, Yu X, Wang P, et al. Implementation of Intraoperative Neuromonitoring for Transoral Endoscopic Thyroid Surgery: A Preliminary Report. J Laparoendosc

Cite this article as: Liu Z, Li Z, Peng X, Zhou B, Lv C, Yi L, Li H, Peng W, Wang Z, Li J. Transoral endoscopic thyroidectomy vestibular approach in a patient with Class III goitre (operative steps and video). Gland Surg 2020;9(5):16051613. doi: $10.21037 /$ gs-20-147
Adv Surg Tech A 2016;26:965-71.

15. Hongjuan W, Fei C, Yongquan Z, et al. Three-dimensional reconstruction of cervical CT vs ultrasound for estimating residual thyroid volume. Journal of Southern Medical University 2019;39:373-6.

16. Anuwong A, Ketwong K, Jitpratoom P, et al. Safety and Outcomes of the Transoral Endoscopic Thyroidectomy Vestibular Approach. JAMA Surg 2018;153:21-7.

17. Wang C, Zhang S, Zhai Y, et al. Analysis of superior thyroid pole through the cervical strap muscles approach:A clinical analysis of 55 patients. Chinese Journal of Practical Surgery 2017;37:1013-5.

18. Naytah M, Ibrahim I, Da SS. Importance of incorporating intraoperative neuromonitoring of the external branch of the superior laryngeal nerve in thyroidectomy: A review and meta-analysis study. Head Neck 2019;41:2034-41.

19. Erol V, Dionigi G, Barczynski M, et al. Intraoperative neuromonitoring of the RLNs during TOETVA procedures. Gland Surg 2020;9:S129-35.

20. Caturegli P, De Remigis A, Rose NR. Hashimoto thyroiditis: clinical and diagnostic criteria. Autoimmun Rev 2014;13:391-7.

21. Sahin M, Cakal E, Ozbek M, et al. Elastography in the differential diagnosis of thyroid nodules in Hashimoto thyroiditis. Med Oncol 2014;31:97. 